\title{
DEBATES
}

\section{Por que se falou tanto da institucionalização das instâncias participativas? O Congresso Nacional e a implementação ou veto às IPs}

\author{
Why the institutionalization of participatory instances was \\ discussed so much? The National Congress and the implementation \\ or veto of PIs
}

\section{Marcos Luiz Vieira Soares Filho}

\section{Resumo}

O institucionalismo histórico aponta para a relevância de forças políticas de manutenção de uma instituição após o seu processo formativo. Com tal preocupação, o objetivo deste artigo é evidenciar que as disputas no Congresso Nacional importam à formulação e à implementação de instituiçóes de participação (IPs). A metodologia consiste na análise de documentos do Congresso sobre o veto ao Conselho Nacional dos Direitos do Idoso (CNDI), de 1990 a 2003, comparados aos da Política e Sistema Nacional de Participação Social (PNPS/SNPS). Dos casos, foram extraídos "pacotes interpretativos" (conceito de Fuks): o conjunto de ideias que fundamentam posiçóes e mobilizam discursos sobre situaçóes. Conclui-se que a forma como seus atores construíram interpretaçóes políticas sobre a formulação e a implementação das IPs perpassaram conjunturas diversas no Congresso Nacional. Ou seja, a conjuntura política possui influência sobre os pacotes interpretativos acerca das IPs e altera a sua implementação.

\section{Palavras-chave}

Participação; Legislativo; Conselho Nacional dos Direitos da Pessoa Idosa; Política Nacional de Participação Social.

\begin{abstract}
The goal of this article is to make evident that disputes in the National Congress matter to the formulation and implementation of participatory institutions (IPs). The methodology consists of analysis of the Congress documents on the veto of the National Council for the Rights of the Elderly from 1990 to 2003. This case is compared to the National Policy and System of Social Participation (PNPS/SNPS). From such cases, we extracted "interpretative packages" (as used by Fuks): the set of ideas from which one takes a stand and that mobilize discourses on a number of situations. In comparative analysis, we conclude that the formulation and implementation processes pass by the National Congress, through the ways that their actors organize internally and mobilize their political interpretations. Furthermore, it is noticed that the interpretative packages are altered by the national political situation that the Congress passes by.
\end{abstract}

\section{Keywords}

Participation; Legislative; National Council for the Rights of the Elderly; National Policy of Social Participation. 


\section{Introdução}

A pergunta do título deste artigo se aproveita de um debate teórico inerente ao institucionalismo histórico. Parte de uma pergunta sobre os condicionantes da manutenção institucional após conjunturas críticas: como e por que as novas instituiçôes criadas se mantêm ao longo do tempo? $\mathrm{Na}$ lógica do institucionalismo histórico, os momentos de conjuntura crítica estão repletos de atores interessados em estabelecer novas diretrizes institucionais, uma vez que momentos de crise oportunizam a ruptura do status quo (FIORETOS, FALLETI e SHEINGATE, 2016). Os mecanismos de manutenção (COLLIER e COLLIER, 2002) são importantes, no âmbito da teoria institucionalista, para explicar por que determinadas instituiçóes se mantêm após as conjunturas críticas em detrimento dos interesses institucionais conflitantes.

A partir da questão institucionalista, o artigo busca entender como as instituiçóes participativas (IPs) foram formuladas/implementadas ou vetadas a partir de posiçôes de atores no Congresso Nacional em conjunturas políticas distintas. A teoria mencionada é apropriada neste artigo porque alerta que não só os momentos de formulação, mas também os momentos conjunturais posteriores importam para o destino de uma determinada instituição. Consequentemente, pretende-se abordar como as IPs estão suscetíveis às disputas políticas nas instituiçôes democráticas tradicionais, mesmo após a sua institucionalização. Apesar de o institucionalismo se propor a observar macroinstituiçôes, suas questóes e a sua lógica podem ser aplicadas às IPs, em função da associação usual, na literatura especializada, de tratar as IPs como instituiçôes no sentido convencional.

Na bibliografia especializada sobre os conselhos públicos e demais IPs, também se apresentou a preocupação com a institucionalização, significando a efetivação e o melhoramento dessas práticas participativas (AVRITZER, 2011). Entretanto, essa expectativa não esperava mudanças conjunturais na política brasileira que pudessem enfraquecer ou deslegitimar a atuação dessas práticas. Isso sugere que não basta observar somente as IPs para entender a sua possibilidade de ação política.

O estudo da institucionalização dos mecanismos participativos significou, para a literatura especializada, a expansão e o enraizamento das instituições de participaçáo (IPs) em setores de políticas públicas e em sistemas políticos representativos (AVRITZER, 2011). Um movimento recente do estudo dos conselhos, principalmente a partir de Guicheney (2019), indica que eles podem ser lidos como uma instituição em si mesma, que integra um setor de políticas públicas e interage com outras instituiçóes e organizaçôes dos diversos níveis de governo, inclusive instituiçóes 
representativas tradicionais da democracia. Essa ideia também esteve presente de forma semelhante em Almeida e Tatagiba (2012, p. 79), que percebem a atuação dos conselhos em "circuitos decisórios": em interação com outras instituiçôes que recebem e enviam-lhes estímulos que estabelecem contingências e dependências. Perceber a IP como uma instituição dentre outras tem como efeito a redução das expectativas de que elas sejam sempre variáveis explicativas. Tomá-las como parte de um sistema de representação e de subsistemas de políticas públicas, por exemplo, torna a pesquisa mais sensível às influências que as IPs sofrem - para então compreender como elas afetam outras variáveis. Essa percepção também está de acordo com o estudo de Romão (2015), para quem a participação pode ser entendida como uma política pública cuja implementação depende dos governos.

As relaçóes entre as instituiçôes de representação democrática e as de participação podem produzir alteraçôes nos desenhos das IPs e nas políticas implementadoras dessas IPs. Se a tendência mais recente na bibliografia do tema é entender os conselhos como uma instituiçáo individualizada, mas integrada a outras, pode-se indagar sobre o processo específico de institucionalização das instâncias colegiadas - porque o processo formativo dos conselhos no Congresso Nacional lança luz às disputas políticas que envolveram a sua institucionalização e que moldaram o alcance da sua atuação, principalmente no sentido de limitá-lo.

O objetivo deste artigo é evidenciar como se desenvolveram disputas políticas no Legislativo sobre a consolidação dos conselhos para argumentar que estes náo estiveram, nem estão, distantes dessas disputas. $\mathrm{O}$ foco do artigo está nas formas como posiçóes divergentes no Congresso Nacional se estabeleceram e como elas se justificaram. Essas posições defendidas acerca das IPs estão suscetíveis às conjunturas políticas divergentes em cada caso a ser observado. O clima político vivenciado no país, em momentos diferentes, é acompanhado por alteraçóes nas percepçóes dos congressistas sobre as IPs.

Para atingir esse objetivo, propóe-se observar dois processos, do Conselho Nacional dos Direitos do Idoso (CNDI) ${ }^{1}$ e o da Política e o do Sistema Nacional de Participaçáo Social (PNPS/SNPS). Serão analisadas as ideias e os discursos de congressistas sobre a formulação, implementação e vetos identificados a partir da análise documental dos processos de aprovação de leis do Congresso Nacional, seus apensados, suas justificativas, mensagens de veto e textos de sustação.

\footnotetext{
${ }^{1}$ Esse é o nome do conselho dado pelo Decreto n ${ }^{\circ} 4.227$, de 2002.
} 
O conceito de pacote interpretativo é uma forma de sintetizar os discursos e ideias que orientam os atores acerca de uma problemática em disputa. $\mathrm{O}$ conceito foi mobilizado anteriormente para descrever, com alguma sistematização, uma visão de mundo, uma forma de problematizar questôes, soluçôes propostas para resolvê-las e a atribuição de responsáveis que integram os discursos de grupos em conflito. A partir da identificação de elementos discursivos, os pacotes sintetizam repertórios argumentativos a partir de frases de efeito e metáforas, por exemplo. São compostos por seis elementos: "núcleo da questão", "núcleo da posiçáo", "caraterização/responsabilização", "causas", "consequências" e "princípios" (FUKS, 1998).

O núcleo da questão explica como determinado grupo ou indivíduo constrói um problema (qual é e por que isso é um problema?), geralmente sobre as açôes de outros grupos ou indivíduos. Questóes não estão dadas no mundo político, são construídas a partir da atenção e enquadramento interpretativo que os atores lhes conferem. O núcleo da posição diz respeito ao que os atores pensam que deve ser feito para a correção do problema. A caracterização/responsabilizaçáo explica as bases e formas, características gerais, que as ideias assumem no pacote interpretativo. São uma justificativa ou desenvolvimento do núcleo da posição e da questão. A responsabilização, especificamente, é interessante nos casos de conflito em que o ator identifica o adversário como responsável pela criação do problema, sendo esse adversário especificado como um tipo, uma caricatura ou como inimigo. As "causas" dizem respeito ao que motiva a problematização e cria o núcleo da questão. As "consequências" estão associadas àquilo que o problema combatido gera no mundo político. E os "princípios" identificam valores ou posiçôes que seriam mais aceitáveis em relação ao núcleo da questão.

Optou-se pelo caso do Conselho Nacional do Idoso (CNDI) em função deste ter sido um dos poucos conselhos - do período dos anos 1990 a início dos 2000 - a ser criado via decreto. Até 2003, foram criados 19 conselhos nacionais, apenas três deles via decreto ao invés de lei: o extinto Conselho Nacional de Desenvolvimento Rural Sustentável (CONDRAF) e os recém-reformulados Conselho Nacional dos Direitos da Pessoa Portadora de Deficiência e o Conselho Nacional dos Direitos do Idoso. Ademais, o CNDI é um caso em destaque por ter uma turbulenta formação: desde a Política Nacional do Idoso, cuja tramitação se iniciou em 1990, esse conselho aguardou aprovação legal para a sua formulação, ocorrida, após vários vetos, apenas em 2002.

A escolha da PNPS/SNPS é justificada pela rejeição e pelo estranhamento à ideia de organizar a participaçáo, como expressão da mudança dos pacotes 
interpretativos em jogo no Congresso Nacional. Coincidentemente, pacotes interpretativos mais fechados à participaçáo estiveram alinhados às mudanças conjunturais observadas entre a década de 1990 e os anos em torno de 2014: enquanto no primeiro caso via-se na conjuntura o interesse de restabelecer a democracia, dentre outas vias, pela participação; no segundo tem-se uma conjuntura com pacotes interpretativos que náo possuem mais esse interesse específico, e outros pacotes totalmente avessos à participação surgem.

$\mathrm{O}$ artigo trabalhará sobre interpretaçóes de congressistas relativas às IPs, cristalizadas em pacotes interpretativos. Ele assume um relativismo em cada pacote, descompromissado com uma realidade objetiva do debate em si. Dessa forma, uma realidade objetivamente posta sobre o significado de cada caso (CNDI e PNPS/SNPS) cede lugar ao diálogo que transcorre no Congresso e nas ideias que cada ator mobilizou para embasar sua posiçáo. Decide-se evitar estabelecer pressupostos duros sobre cada caso para que sejam apontadas as razóes de cada posicionamento, restando a comparabilidade dos casos nas ideias apresentadas e nas conjunturas políticas que permeiam cada experiência. Com isso, a seleção dos casos gira em torno das conjunturas que afetam ideias e resultados muito diversos.

Há diferença significativa entre os dois casos, destacadamente em relação à conjuntura e em relação à magnitude das medidas. É razoável atribuir o veto à PNPSSNPS ao fato de serem políticas de maior envergadura, a alterar as configuraçóes de todo um setor. Essa dimensão da PNPS-SNPS pode ter motivado uma reação mais enérgica por parte oposição. Ao passo que a formulação de um conselho - evento de menor envergadura - possa ser visto como menos problemático para os possíveis opositores. Ademais, deve-se reconhecer que a própria comparabilidade dos casos pode estar ameaçada, considerando-se as diferenças entre eles.

Entretanto, a escolha de compará-los quer evidenciar que a conjuntura importa. A conjuntura será interpretada a partir das configuraçóes dos pacotes interpretativos e a forma como eles evidenciam a mudança de leitura sobre a participaçáo institucionalizada no Congresso. A formulação do CNDI, após vários vetos, indica uma conjuntura favorável à criação de inúmeras IPs, em vários setores de políticas e níveis de governo. Ao passo que, mais recentemente, vê-se uma "revolta" generalizada contra a ideia de participação, exemplificada pelos discursos no Congresso contra a PNPS-SNPS. Mas, mais que isso, na conjuntura mais recente, os esforços contra a participação culminaram na tentativa de extinguir a maior parte das formas de 
participação institucionalizada - Decreto $\mathrm{n}^{\circ} 9.759$, de 11 de abril de $2019^{2}$ - indo muito além do veto à PNPS-SNPS.

A escolha dos dois casos se dá em função de evidenciarem conjunturas muito diversas que têm um papel na explicação das razôes de formular, vetar ou implementar as IPs, apesar da diferença observada sobre sua magnitude - que poderia explicar os esforços de veto ou formulação observados. A observação de cada caso em comparaçáo quer representar as mudanças conjunturais que moldam e explicam algumas das ideias expostas no Congresso acerca da participação institucionalizada. A mudança de ideias em relação às IPs foi dada pela análise das conjunturas apresentadas em cada caso da comparação. Dessa forma, pretendeu-se uma comparação de conjunturas expressas em cada caso.

Essa introdução é seguida por uma seção sobre o debate teórico acerca das IPs e a sua relação com instituições democráticas tradicionais e como o institucionalismo histórico justifica a observação de tal fenômeno. A segunda seção do desenvolvimento aborda o caso do Conselho Nacional dos Direitos do Idoso (CNDI); a terceira, o caso do Sistema e da Política Nacional de Participação Social (PNPS/SNPS), seguida pelas consideraçóes finais.

\section{IPs e Congresso Nacional, por onde começar?}

É desafiador definir uma bibliografia que dê conta das influências do Legislativo Nacional sobre as instituiçóes de participação (IPs) - especificamente sobre os conselhos. Com fins de ilustração, realizou-se uma busca no mecanismo Google, restrita ao sítio eletrônico "scielo.br", a partir das palavras-chave: "conselhos" ou "conselho" ou "participação" e "legislativo" ou "congresso" ou "senado" ou "câmara", com tais palavras permutadas de várias formas (SIMIS, 2010; POGREBINSCHI; SANTOS, 2011; SOUZA, 2011).

O trabalho de Simis (2010) observa o porquê de o Conselho de Comunicação Social náo ter sido implementado e ter ficado 14 anos inativo após formulado, atribuindo como causa a sua dinâmica no Congresso Nacional. Conclui que "guerras de posição" no Congresso conseguiram imobilizar a implementação desse conselho. A autora identifica essa arena como relevante para o Conselho, embora não se preocupe com aprofundamentos teóricos da questão.

Pogrebinshi e Santos (2011) estudam a relação entre as conferências de políticas e o Congresso Nacional. Evidenciam que as conferências animam agendas do

\footnotetext{
2 "Extingue e estabelece diretrizes, regras e limitações para colegiados da administração pública federal".
} 
Congresso, sendo esse permeável às instâncias deliberativas e participativas. Essa permeabilidade permite entender melhor as relaçôes entre IPs e o Legislativo, de forma a atacar a percepção de que seriam instituições antagônicas. A complementaridade sugerida nessa relação conjunta fortaleceria, no argumento dos autores, a legitimidade de ambas as instituiçóes. $O$ trabalho traz evidências empíricas para a recusa de uma interpretação dualista entre representação e participação, há muito combatida (LÜCHMANN, 2007) e neste artigo continuada.

Os orçamentos participativos (OPs) foram estudados como variável explicativa a alterar a estratégia do Partido dos Trabalhadores (PT) e, consequentemente, a relação entre o Executivo e o Legislativo municipal (SOUZA, 2011). Souza (2011) objetivou entender o OP como parte da estratégia do PT para se consolidar como uma opção de governo nacional, uma vez observada pela autora a relação positiva entre experiências bem-sucedidas de OP e o crescimento do partido. Secundariamente, a autora sustentou a tese de que a implantação do OP altera as politics das policies envolvidas na relação Executivo-Legislativo municipal. É, portanto, trabalho de enorme relevância por inserir a leitura da IP no contexto da arena política governamental e partidária, um caminho pouco explorado.

A relaçáo entre o sistema representativo tradicional $e$ as instituições participativas já foi problematizada em outras pesquisas, referenciadas, principalmente, em Lüchmann $(2007,2011)$. Da autora desdobraram-se análises sobre a existência de relaçôes representativas no interior dos conselhos. Nos conselhos há a representação dos beneficiários ou dos interessados diversos na política pública relacionada ao setor fato este que orientou para a necessidade de uma maior sensibilidade teórica para a função representativa operada nos conselhos. Lüchmann (2007) sugeriu que as instituiçôes democráticas tradicionais guardam relaçôes específicas com a representação nas IPs.

As interaçôes institucionais das IPs são reforçadas por outras leituras que enfatizam uma posição relacional. Para Lüchmann (2007), a desproporção de forças institucionais subjuga as IPs a um plano secundário, sendo elas o elo mais fraco entre as instituiçôes. Para Almeida e Tatagiba (2012, p. 82):

Essa confusão [entre a função deliberativa dos conselhos e a sua autonomia político-institucional] nubla o reconhecimento da especificidade do tipo de luta política que pode ser travada via conselhos. Eles são estratégias de lutas por dentro do Estado, visando sua democratização, e não sobre ou paralelamente a essa instituição. Reconhecer essa especificidade é 
fundamental para superar as avaliaçôes marcadas por frustraçóes decorrentes de expectativas que os conselhos não podem cumprir, o que gera imobilismo político.

Para Guicheney (2019, p. 78):

Os conselhos, por exemplo, são instituiçóes vinculadas ao Poder Executivo
nos diferentes níveis da federação e estão imersos na arquitetura
institucional de um setor de policy específico ou de uma área transversal.
Eles não são autônomos em relação ao restante da administraçáo pública
e, a depender do nível federativo, estão geralmente ligados a ministérios,
secretarias municipais/estaduais ou, mesmo, a gabinetes da prefeitura,
sendo deles dependentes para manutenção de suas condiçóes básicas de
funcionamento. Estão, portanto, associados à estrutura de gestão das
políticas no Executivo e devem ser interpretadas no interior dessa estrutura
institucional.

Essas autoras permitem entrever um problema de pesquisa referente às relaçóes assimétricas e de veto que as instituiçôes democráticas tradicionais acarretam sobre as de participação. Para as autoras, o conselho está posto em relação ao Poder Executivo dos municípios. Porém, elas não se aprofundaram em problematizar as influências diretas entre o Legislativo e as IPs e, principalmente, os vetos. Esse aspecto possui relevância porque os conselhos são institucionalizados pelas instituiçóes tradicionais da democracia, por meio de leis ou decretos.

Tais trabalhos levaram em conta as interações do conselho com o Executivo, sendo elas definidas pelos marcos institucionais que legaram ao conselho tal ou qual competência de deliberar, avaliar ou vetar. Entretanto, raramente se ponderou sobre o que definiu esses desenhos institucionais dos conselhos. Os processos formativos dos conselhos evidenciam que eles foram idealizados, problematizados e disputados entre coalizóes no Congresso Nacional. O processo formativo é uma variável relevante para os desenhos institucionais e para o "grau de institucionalizaçáo" dos conselhos, pois mostra em que medida foram implementados, apoiados ou vetados e indesejados.

Essa observação se associa a pressupostos do institucionalismo histórico, uma vez que alteraçóes conjunturais importam para as instituiçôes. Conceitos-chave de tal teoria argumentam que processos políticos são estruturados no tempo e espaço. Os eventos históricos reestruturam ideias e instituiçóes, de forma a condicionar os resultados das açôes de atores ao longo do tempo (HALL, 2016). Dessa forma, conjunturas críticas e dependência de trajetória se tornaram parte do vocabulário de tal 
teoria. A primeira explica como períodos de crise possibilitam alteraçôes radicais no status quo a serem aproveitadas pelos atores políticos. Ao passo que o segundo conceito se relaciona à perpetuação de instituiçôes criadas nessas crises, que estruturaram forças a protegê-las e mantê-las ao longo do tempo, tornando-as resistentes a interesses adversos.

Nessa dinâmica, também são considerados os mecanismos de reprodução: são fatores suficientemente relevantes para manter um resultado institucional estável após o desaparecimento das forças que os produziram originalmente (SOIFER, 2012). Definiçấo aprofundada é dada em Collier e Collier (2002) ao considerarem que a estabilidade de novos padrôes institucionais não é um resultado automático das conjunturas críticas - os novos padrôes devem ser perpetuados constantemente por processos políticos e institucionais que estimulem a perpetuação em detrimento à renovação institucional, restando aí a definição de mecanismos de reprodução.

Não se pretende argumentar a existência de uma conjuntura crítica no contexto brasileiro recente, uma vez que tal esforço exige um distanciamento maior em relação ao objeto, além da própria diferença de porte entre as IPs e os objetos de interesse da teoria em questáo. No entanto, do argumento institucionalista quer-se enfatizar que as mudanças nas instituiçôes estão condicionadas por seu meio - pelas disputas dadas em seu "tempo e espaço". Se o período de redemocratização e as suas respectivas ideias sobre a participação se esvaem, haverá forças políticas suficientes para manter as suas heranças? Novas forças políticas serão, necessariamente, favoráveis às IPs? Essas perguntas argumentam que a continuidade das instituiçôes depende da organização de movimentos de manutençấo ou de contrariedade a elas. Os estudos tradicionais sobre as IPs observaram a sua institucionalização, preocupados com o seu enraizamento e difusão territorial, mas a questão da institucionalização deve ser também observada sob o prisma das forças de reprodução e dos conflitos que podem causar danos às instituiçóes participativas, cujas disputas se manifestam, dentre outras arenas, no Congresso Nacional.

Processos de disputa sobre as IPs se deram no Congresso Nacional em momentos políticos muito distintos. Nos anos 1990 observou-se uma conjuntura política muito favorável às IPs, em busca de uma redenção democrática - a recuperação da democracia após anos de ditadura. Por essa razão, parte dos estudos ali localizados estáo preocupados com o aprofundamento democrático potencialmente trazido por tais instituições. Entretanto, mudanças na conjuntura política nacional alteraram a percepção de legisladores sobre o espaço da participaçáo institucionalizada - isso como 
um sintoma do já ascendente movimento conservador em esferas institucionalizadas da política (LACERDA, 2018; SANTOS e TANSCHEIT, 2019).

A presença de movimentos conservadores no Congresso altera o clima político e as ideias presentes na instituição. De acordo com Santos e Tanscheit (2019), houve uma ruptura na representação da direita brasileira, marcada pela ascensão gradual de uma direita mais radical. Para o que importa neste artigo, essa nova direita é caracterizada como livre das preocupaçôes de fortalecimento da democracia, e está temporalmente localizada na atuaçáo do impeachment da ex-Presidente Dilma Rousseff. Naquela leitura, a nova direita compóe uma descontinuidade com a direita antiga, ao descartar a preocupação democrática e abraçar um autoritarismo neoliberal.

Lacerda (2018) também explora as recentes mudanças no Congresso Nacional ao identificar nele o surgimento e a articulação crescente de um movimento conservador. A coleta de dados de votaçóes, proposiçóes, discursos e perfil dos deputados da legislatura iniciada em 2015, permite à autora identificar uma direita defensora de valores tradicionais e do liberalismo econômico. Mais uma vez, é também identificado o descompromisso com o fortalecimento democrático e a expansão da participação política.

Pode-se falar de uma mudança na composiçáo do Congresso Nacional que ocasiona mudanças de agenda e preferências, de forma genérica, observadas nos últimos anos e associadas ao impeachment da Presidente Dilma Rousseff. O objetivo de remeter a essa fase é dar relevo à mudança conjuntural que perpassa o Congresso e, assim, poder destacar os seus efeitos sobre a participaçáo institucionalizada. Não se quer aqui focalizar a existência, ou não, de um movimento articulado conservador, mas destacar que: disputas no Congresso Nacional, em conjunturas distintas, importaram para a definiçáo do desenho dos conselhos, tornando-se o Congresso mais afeito aos vetos quando da ascensão do conservadorismo.

\section{O caso do Conselho Nacional dos Direito do Idoso}

A formulação do Conselho Nacional dos Direitos do Idoso $(\mathrm{CNDI})^{3}$ foi pretendida inicialmente na Política Nacional do Idoso (PNI). Essa política é resultante da articulação de movimentos de aposentados e pensionistas em confluência às associaçôes técnico-científicas em diálogo com atores do Congresso Nacional (PAZ, 2001). O conselho era visto por tais movimentos e associaçóes como parte integrante

\footnotetext{
${ }^{3}$ Esse é o nome dado ao conselho em sua primeira formulação. Cabe destacar que ele passou por reformulaçóes e é, até então, o Conselho Nacional dos Direitos da Pessoa Idosa.
} 
de uma política comprometida com a proteção do idoso e a sua inclusão social pela via da participação política (SOARES FILHO, 2018). O conselho era também, e principalmente, uma forma de coordenar e exercer o controle social sobre as açóes públicas - ideias sobre a participação bastante típicas ao seu período de formulação, a década de 1990 (GOHN, 2011).

Pode-se perceber que a formulação do Conselho do Idoso está de acordo com ideias democratizantes amplamente difundidas nos anos de 1990 e pós-constituinte. Essas ideias gerais estão associadas à reconstrução democrática do período tanto em relação ao direito social quanto aos direitos políticos. Ademais, o processo de formulação do conselho conta com a participação de movimentos sociais atuantes desde a constituinte e politicamente ativos na reconstrução democrática (HADDAD, 2001).

A receptividade de determinados congressistas foi um aspecto-chave para a institucionalização dessa política, resultada de interaçôes Estado-sociedade. A PNI se tornou o Projeto de Lei (PL) n ${ }^{\circ} 112 / 1990$ no Senado e foi encaminhada à Câmara dos Deputados, tornando-se o PL n ${ }^{\circ} 5.710 / 1990$. Ao fim da tramitação, tornou-se a Lei ${ }^{\circ}$ 8.842, de 4 de janeiro de 1994.

Entretanto, a constituição do Conselho Nacional do Idoso foi um aspecto de difícil formulação. O PL n 112 do Senado Federal, que "Fixa as diretrizes para a política nacional de assistência ao idoso, e dá outras providências", visa criar o “[...] Conselho Nacional de Assistência ao Idoso integrado por representantes das instituiçôes federais de assistência social dos governos estaduais e municipais e de organizações assistenciais no âmbito nacional” (BRASIL, 1990, p. 14-15).

Foram apensados ao $\mathrm{PL} \mathrm{n}^{\circ} 112$ outros projetos de lei que tratavam da criação de conselhos da política do idoso: o Conselho Nacional de Assistência ao Idoso (PL n ${ }^{\circ}$ 323/1991), o Conselho Nacional dos Direitos do Idoso (PL n 1925/1991) e o PL n ${ }^{\circ}$ 2.946/1992, que sugeria a criaçáo do Conselho Nacional do Idoso (CONID).

A justificação da proposta legislativa de autoria da Subcomissáo do Idoso do Senado Federal estava baseada na necessidade de integrar os serviços existentes em saúde e assistência social, principalmente para o atendimento à crescente população idosa. O conselho não é mencionado na justificação da proposta.

No entanto, o documento Relatório sobre as atividades da Subcomissáo do Idoso do Senado Federal continua a análise do PL recebido. É relatado que "[...] foram realizadas audiências públicas para obter depoimentos e receber sugestôes de autoridades diretamente ligadas à assistência aos idosos, assim como de representantes 
da terceira idade", e que é resultado do trabalho da subcomissão a seguinte ponderação, dentre outras:

Com a finalidade de definir e fiscalizar as medidas políticas, econômicas e sociais de assistência ao idoso, foi proposta a criação de um organismo formado por representantes governamentais e da sociedade civil que coordene a ação de órgáos e programas já existentes e promova o melhor atendimento ao idoso nas áreas de saúde, cultural, social e educacional, atuando, inclusive, na área de planejamento e na formação de recursos humanos especializados. (BRASIL, 1990, p. 17).

Essa ponderação informa que a subcomissão fortalece a necessidade do conselho como organismo de coordenação mobilizado por atores sociais e estatais. Essa ideia é incluída nas conclusóes do relatóriót

Para a implementação dessa política social foi sugerida a criação de um Conselho Nacional de Assistência ao Idoso, formado de representantes governamentais e institucionais, com a finalidade de promover a assistência médico-social, defender direitos e interesses, conjugar recursos, divulgar informaçôes e proporcionar oportunidades de realização pessoal e de integração social aos idosos. Como conclusão dos trabalhos realizados pela Subcomissão do Idoso, estamos apresentando projeto de lei, que "fixa diretrizes para a política nacional de assistência ao idoso, e dá outras providências", instituindo o Conselho Nacional de Assistência ao Idoso, cujas principais atribuiçôes se encontram especificadas no referido projeto. (BRASIL, 1990, p. 19).

A redação final do projeto de lei contempla o Conselho Nacional de Assistência ao Idoso em seu décimo artigo.

De acordo com Soares Filho (2019, p. 15), na Câmara dos Deputados, a Comissão de Seguridade Social e Família relata que "O Ministério do Bem-Estar Social, através da Secretaria da Promoção Humana, apoiou a realização do I Encontro Técnico dos Conselhos Estaduais do Idoso" (BRASIL, 1990, p. 28), que visou avaliar o PL no 5.710, de 1990. O evento contou com a participaçáo de conselhos estaduais e municipais do idoso de várias regióes (BRASIL, 1990, p. 28). Na mesma relatoria, que data de 24 de maio de 1993, é anexado um substitutivo que incorpora uma redação

\footnotetext{
${ }^{4}$ Ele é assinado em 21 de junho de 1990 pelo Presidente da subcomissão, Carlos Patrocínio, Jutahy Magalhães, Relator, Marcos Mendonça, Mário Maia e João Lobo.
} 
alterada, em comparação com o PL do Senado e os PLs apensados, instituindo o Conselho Nacional do Idoso, ao invés do Conselho Nacional de Assistência ao Idoso. A escolha por tal nome e formato, diante das alternativas, parece ter resultado daquele encontro técnico.

Esse PL criou, nos artigos $\mathrm{n}^{\circ} 11$ a 18, o Conselho Nacional do Idoso. O artigo 11 o conceituou e o filiou ao ministério responsável pela Política de Assistência Social. Os demais artigos detalham as competências, a organização interna e a distribuição dos conselheiros entre sociedade civil e Estado.

Todos esses artigos foram vetados por pareceres e emendas sugeridas ao PL $\mathrm{n}^{\circ}$ 5.710/1990, mediante a justificativa:

\begin{abstract}
Entretanto, ao criar o Conselho Nacional do Idoso, a proposta contraria o art. $61, \$ 1$, II, “e”, que estabelece competir privativamente ao Presidente da República a iniciativa das leis que disponham sobre criação, estruturação e atribuiçôes dos Ministérios e órgãos da administração pública $[\ldots]$.

Além disso, o parágrafo único do art. 18 confere atribuição à Secretaria da Promoção Humana, órgão integrante da estrutura do Ministério do BemEstar Social, nos termos do art. 19, XV, "d", da Lei no 8.490, de 19 de novembro de 1992, que "dispóe sobre a organização da Presidência da República e dos Ministérios e dá outras providências", o que contraria, igualmente, o citado art. 61, $\$ 1^{\circ}$, II, e, “da Carta Política”. (BRASIL, 1994).
\end{abstract}

Assim, a forma sugerida para a Política Nacional do Idoso prevê a exclusão dos artigos para se desfazer de um vício de inconstitucionalidade: “[...] compete privativamente ao Presidente da República a organização e o funcionamento da administração federal. A criaçáo do Conselho Nacional do Idoso, na estrutura de Ministério, portanto, é vedada à iniciativa de parlamentar (CF. art. 84, 111)" (BRASIL, 1990, p. 78).

De fato, o projeto de lei foi proposto incialmente nas casas legislativas, ao contrário, por exemplo, da Lei Orgânica da Assistência Social, que pôde criar o Conselho Nacional de Assistência Social, mas que foi proposta pelo Presidente da República ao Congresso. Apesar de a participação de setores e agentes específicos da sociedade terem influenciado tal política, não se pôde criar o Conselho Nacional do Idoso junto à Política Nacional do Idoso, nos anos 1990. 
O Estatuto do Idoso, PL do Senado n ${ }^{\circ} 3.561$, de 1997, PL da Câmara n ${ }^{\circ} 57$, de 2003 e, por fim, Lei $\mathrm{n}^{\circ}$ 10.741, de 2003, visou implementar a PNI e deu continuidade ao esforço de criaçáo do conselho. Vários PLs foram apensados a esse estatuto, portanto, e destaca-se a proposiçáo do Senador Paulo Paim para orientar a análise. Os demais projetos não visaram a criação de um conselho nacional, apenas mencionaram atribuiçóes àquele conselho vetado na PNI. O Projeto do Senador Paim, portanto, insiste na continuidade da busca pela formulação do conselho.

No PL n ${ }^{\circ} 3.561 / 1997$, são feitas mençóes e citadas atribuiçôes aos conselhos nacional, estaduais e municipais. A criação em si assim está redigida no PL:

Art. $4^{\circ}$ - ficam instituídos os Conselhos Nacional, Estaduais, do Distrito Federal e Municipais do Idoso, que serão permanentes, paritários e deliberativos, compostos por igual número de representantes dos órgáos e entidades públicas e de organizaçóes representativas da sociedade civil ligadas à população idosa.

Parágrafo Único - A organização dos Conselhos será feita por regimento próprio, observadas as diferentes instâncias político-administrativas. (BRASIL, 1997, p. 231).

$\mathrm{O}$ artigo $5^{\circ}$ estabelece as competências do Conselho: "[...] a formulação, coordenação, supervisão e avaliação da política do idoso" (BRASIL, 1997, p. 231). A partir desse artigo, são mencionadas as atribuições da União, através de seus ministérios.

É sintomático que o Conselho Nacional projetado por Paim consista apenas em dois artigos, um deles com parágrafo único, em comparação com o conselho vetado na PNI, que se estendia do $11^{\circ}$ ao $18^{\circ}$ artigo, com vários parágrafos. Há, inclusive, outra diferença entre eles: a abstençáo da filiação institucional do conselho a ministérios no projeto do Estatuto do Idoso. Essa simplificação do desenho institucional do conselho indica que o Estatuto do Idoso o abrandou com a intençáo de formulá-lo sem ferir a Constituição Federal.

Ainda assim, agora na Câmara dos Deputados, o relator da Comissão Especial escreve:

Todavia, os Projetos apresentam algumas inconstitucionalidades, formais ou materiais, a seguir assinaladas. Os Projetos de Lei $n^{\circ}$ s 3.561, de 1997, [...], violam o art. 61, $\$ 1$ o , 11, alíneas "b" e "e", da Constituição" Federal, que trata da iniciativa privativa do Presidente da República para leis que disponham sobre a organização administrativa, serviços públicos, criação, 
estruturação e atribuições dos Ministérios e dos órgãos da Administração Pública. [...] Tais inconstitucionalidades, constantes dos arts. $4^{\circ}, 5^{\circ}, 6^{\circ}, 11$, [...] devem ser extirpadas. (BRASIL, 1997, p. 330).

A justificação do veto ao art. $4^{\circ}$ não passa dessas linhas, resumindo-se à mesma razão apresentada na PNI. O substitutivo do PL apresentado após a relatoria altera dramaticamente o conteúdo do artigo $4^{\circ}$, versando sobre a punibilidade pela negligência ou violência direta contra o idoso. Por fim, a Lei $n^{\circ} 10.741 / 2003$ menciona o Conselho Nacional citado, de forma vazia, na PNI.

O Conselho Nacional dos Direitos do Idoso foi criado pelo decreto $\mathrm{n}^{\circ} 4.227$, de 13 de maio de 2002. Havia movimentação interna no Senado para a sua criação. É o que mostra uma pesquisa realizada no Sistema de Informaçóes do Congresso Nacional (SICON), buscando em discursos de parlamentares, proferidos até a data de 14 de maio de 2002, as palavras-chave "conselho nacional" e "idoso". A partir dos achados dessa busca pôde-se perceber atuaçóes para a consecução do conselho.

Essa pesquisa revelou que o Presidente da Subcomissão Permanente do Idoso, o Senador Leomar Quintanilha (PFL-TO), foi um entusiasta da participação institucionalizada. Ele incentivou a expansão dos conselhos municipais e estaduais distribuindo cópias de projeto de lei para servirem como modelo. No entanto, aborda também a questão do Conselho Nacional:

Em nível federal [...] é de fundamental importância a criação e implementação do Conselho Nacional do Idoso. Esse Conselho só poderá ser criado por iniciativa do Poder Executivo. Devido a esse fator, a Subcomissão Permanente do Idoso desta casa, já solicitou audiência com Sua Excelência o Ministro da Justiça, Doutor Aluísio Nunes Ferreira, para sugerir a implantação, no seu Ministério, desse importante Conselho. Aliás, já estivemos com a Secretária Nacional de Assistência Social e responsável pela Política Nacional do Idoso, Doutora Wanda Engel, que defende a criação do Conselho Nacional do Idoso no Ministério da Justiça. Esse órgão, o Conselho [...], a partir de sua implantação, será o responsável pela fiscalização da Política Nacional do Idoso. Esse é um fator importante e o motivo principal para que ele náo seja criado no Ministério da Previdência e Assistência Social. Como é que um órgão subordinado ao Ministério da Previdência, vai fiscalizar a atuação desse Ministério? [...] O nosso país já possui a Política Nacional do Idoso. Apenas está faltando a criação e implantação do Conselho Nacional do Idoso, que é a maior "bandeira" da Subcomissão Permanente do Idoso, no Senado Federal (BRASIL, 2002b). 
Nesse discurso é defendida uma estratégia para a criaçáo do conselho que consiste na abordagem direta a membros do Executivo Federal, a fim de incentivá-los a instaurá-lo. O resultado dessas abordagens é relatado no discurso do mesmo senador um mês depois:

Ora, Sr. Presidente, [...], a questão relacionada ao idoso, balizada pela Lei $n^{\circ} 8.842$, teve, na sua concepção, os artigos que diziam respeito à criação do Conselho Nacional do Idoso vetados pelo fato de ser aquele instrumento legal originário do Poder Legislativo, e o Conselho do Idoso é matéria que deve ser oriunda do Poder Executivo. Por essa razão, consideramos de fundamental importância essa visita de estímulo ao Ministro Aloysio Nunes para a criação do Conselho Nacional do Idoso, com o objetivo de avaliar e balizar a política hoje em prática de apoio e valorização do idoso e, sobretudo, o esforço que se desenvolve em diversas instituiçôes públicas ou privadas, com vistas à sua reinserção no mercado de trabalho, ao seu convívio com a sociedade e com as atividades diversas. Portanto, gostaria de registrar, nesta tarde, a presença positiva e a receptividade demonstrada pelo Ministro Aloysio Nunes Ferreira aos representantes da Subcomissão do Idoso que foram lhe propor a criação do Conselho Nacional do Idoso. (BRASIL, 2002a).

Esta pesquisa não teve como associar as ações dessa comissão ao Decreto ${ }^{\circ}$ 4.227. Cabe dizer que esses discursos foram realizados, respectivamente, no dia 21 de fevereiro e no dia 5 de março de 2002, pouco tempo antes da publicação do decreto, em 13 maio do mesmo ano. O senador e a subcomissáo podem ter sido intermediários na formulação do conselho ao idealizar a integração com o Executivo. Ademais, o decreto vinculou o conselho ao Ministério da Justiça, como pretendeu o Senador Leomar Quintanilha: "Art. $2^{\circ}$ Fica criado, na estrutura básica do Ministério da Justiça, o Conselho Nacional dos Direitos do Idoso - CNDI, órgáo de caráter consultivo” (BRASIL, 2002c).

A partir dessas movimentações para a formulação do conselho, pode-se sintetizar o pacote interpretativo das ideias dos atores envolvidos de forma genérica, uma vez que os discursos e as ideias mobilizadas no sentido da criação e do veto de um conselho do idoso foram partidariamente difusas: 
Quadro 1 - Posições no Congresso Nacional até 2002 sobre um conselho do idoso

\begin{tabular}{|l|l|}
\hline Núcleo da Questáo & $\begin{array}{l}\text { Um conselho é instância desejável para a implementação e controle da } \\
\text { política do idoso, mas não pode ser criado na estrutura do Executivo pelo } \\
\text { Congresso Nacional. }\end{array}$ \\
\hline Núcleo da Posiçáo & $\begin{array}{l}\text { Vetar a formulação do conselho e convencer atores do Executivo Federal a } \\
\text { adotar a ideia. }\end{array}$ \\
\hline $\begin{array}{l}\text { Caracterizaçóes/ } \\
\text { Responsabilizaçáo }\end{array}$ & $\begin{array}{l}\text { A inconstitucionalidade da instauração do conselho é motivação técnica } \\
\text { incontornável, não havendo responsáveis para tanto. }\end{array}$ \\
\hline Causas & Técnica legislativa. \\
\hline Consequências & Inconstitucionalidade. \\
\hline Princípios & Legalidade e constituição. \\
\hline
\end{tabular}

Fonte: Elaboração própria.

Em relação à conjuntura política observada no período, os interesses pela redemocratização e a valorização das instituiçóes democráticas como um bem em si mesmo podem explicar o pacote interpretativo em relaçáo à desejabilidade do CNDI. Esses valores subjacentes ao período também podem explicar a mobilização de indivíduos na busca de soluçôes para os empecilhos à formulação do conselho e, ainda além, o engajamento de mais atores políticos nesse movimento.

\section{O caso da Politica e do Sistema Nacional de Participação Social (PNPS/SNPS)}

A maior política de implementação das IPs, em termos de abrangência e de aprofundamento da especificação das relaçóes entre IPs e burocracias, se deu pelo Decreto Presidencial n 8.243, de 23 de maio de 2014. As ideias e discursos que envolveram a criação dessa política não são recentes e foram explorados já em Soares Filho (2019). Nesse trabalho, o autor mobilizou uma entrevista concedida por um dos idealizadores da PNPS/SNPS, Pedro Pontual, à Gurza Lavalle e Szwako (2014) para sistematizar os pacotes interpretativos favoráveis à participação.

A implementaçáo da política de participação social é pensada a partir dos anos 2000. Atores identificados como do "campo democrático popular" visaram retomar o fôlego do discurso participacionista, que completava entáo 30 anos. Essa movimentação diagnosticou a necessidade de avaliar o desempenho das IPs. O resultado da avaliação foi que as IPs possuíam desempenhos e contextos muito heterogêneos; além de que a sociedade civil e os movimentos sociais entendiam o ato 
de participar de forma muito diversa, existindo muitas visóes diferentes; esses dois elementos caracterizaram o diagnóstico como causado por uma espécie de amorfismo, como sinônimo de "desarticulação", em função da falta de regulações e planejamentos mais gerais para as IPs (GURZA LAVALLE e SZWAKO, 2014, pp. 94, 95). Concluiuse ser necessário pensar uma forma de "arquitetar a participação" para homogeneizar resultados e processos. A ideia ganhou força e apoio burocrático no governo Dilma, com uma secretaria especializada no assunto. A partir daí, a ideia de "arquitetar" evoluiu para uma ideia de sistematizar a partir de uma política pública da participação social, que chegou a ser formulada na PNPS/SNPS (SOARES FILHO, 2019; GURZA LAVALLE e SZWAKO, 2014).

Tanto as ideias quanto os atores dessa conjuntura política estão em sintonia com aquelas ideias dos anos 1990 de fortalecimento das instituiçóes democráticas. Eles podem ser vistos como uma renovaçáo das ideias daquele outro período em relaçáo à participação. Os atores entendem, em ambas as conjunturas, que a participação institucionalizada é uma forma de aprofundamento democrático.

A PNPS/SNPS ataca o amorfismo institucional, bem como o conceitual, associado às grandes discrepâncias de efetividade das IPs em setores de políticas e regióes diversas. A PNPS/SNPS busca aumentar o rigor conceitual e organizacional das IPs ao referenciá-las em um documento de conteúdo mais específico nesses temas e de forte validação institucional. Isso porque a Constituição Federal foi um dos poucos instrumentos legais para tornar as IPs palpáveis, ou mais organizadas em suas atribuiçóes e legitimidade. Portanto, a implementação das IPs passaria pela sua regulação, aprimoramento conceitual e organização sistemática em uma norma geral.

A partir do exposto, tem-se o seguinte pacote interpretativo a defender a implementação das IPs:

Quadro 2 - PNPS: Implementação e consolidação da participação social

\begin{tabular}{|l|l|}
\hline Núcleo da Questáo & $\begin{array}{l}\text { As experiências participativas cresceram em número, mas a questão } \\
\text { qualitativa ainda pesa. Há a percepção de que as IPs apresentavam resultados } \\
\text { muito heterogêneos sobre políticas públicas, além de serem pouco } \\
\text { articuladas e muito fragmentadas entre si. }\end{array}$ \\
\hline Núcleo da Posição & $\begin{array}{l}\text { Deve-se estruturar a participação social em uma política nacional, de tal } \\
\text { forma que ela se institucionalizasse como política de Estado. }\end{array}$ \\
\hline $\begin{array}{l}\text { Caracterizaçóes/ } \\
\text { Responsabilizaçáo }\end{array}$ & $\begin{array}{l}\text { Faltam informaçóes sistemáticas para localizar e descrever as experiências } \\
\text { participativas em termos de efetividade/não identifica responsáveis diretos, }\end{array}$ \\
\hline
\end{tabular}




\begin{tabular}{|l|l|}
\hline & $\begin{array}{l}\text { vê a necessidade de uma política como o próximo passo para o avanço das } \\
\text { IPs. }\end{array}$ \\
\hline Causas & Vazio institucional regulatório. \\
\hline Consequências & Falta de organização e ordenamento. \\
\hline Princípios & Efetividade e organização. \\
\hline
\end{tabular}

Fonte: Soares Filho (2019, p. 13).

A PNPS e o SNPS atiçaram um movimento reacionário altamente conservador no Congresso Nacional. As ideias e os discursos desses atores tiveram um tom elevado, expresso em justificativas de decretos com a finalidade de sustar a PNPS/SNPS: o Projeto de Decreto Legislativo (PDL) de Sustação de Atos Normativos do Poder Executivo $n^{\circ} 1.491 / 2014$ e, no Senado Federal, PDL n ${ }^{\circ} 147 / 2014^{5}$.

Tal projeto "Susta a aplicação do Decreto no 8.243, de 23 de maio de 2014, [...] e dá outras providências" (BRASIL, 2014c), e foi apresentado em 30 de maio de 2014, apenas uma semana após a apresentação do Decreto ${ }^{\circ} 8.243$, de 23 de maio de 2014, instaurador da PNPS/SNPS - ainda tramitado em regime de urgência, conforme requerido pelo autor, Mendonça Filho.

Serão analisados trechos da justificativa que acompanha o texto inicial da proposta legislativa em questão. Para os autores, existem interesses subversivos na PNPS:

Essas breves linhas retratam de maneira absolutamente clara qual a intenção da Presidente da República: implodir o regime de democracia representativa, na medida em que tende a transformar esta Casa em um autêntico elefante branco, mediante a transferência do debate institucional para segmentos eventualmente cooptados pelo próprio Governo. $\mathrm{O}$ ato em questão náo comporta outra leitura. (BRASIL, 2014c, p. 13).

Esses interesses seriam sintomas de um autoritarismo, o que foi assim argumentado:

Ao dar prerrogativa aos movimentos sociais adeptos da ideologia do grupo político no poder nos últimos doze anos e fomentar a sua ampliação; ao

\footnotetext{
${ }^{5}$ Os projetos de decretos legislativos regulam matérias de competência exclusiva do Poder Legislativo e o seu processo de aprovaçáo parte da casa iniciadora, nesse caso a Câmara dos Deputados, e parte para a casa revisora, nesse caso o Senado.
} 
submeter órgãos da Administração Pública [...] às decisôes tomadas no âmbito do Programa; e ao promover o controle dos movimentos sociais, a Presidente da República, na verdade, está criando seu próprio Estado, suas próprias regras, suas classes de cidadãos, incorporando, assim, a figura de Luís XIV, quando disse: L'État c'est moi. A necessidade de se combater esta insanidade consolidada no decreto $n^{\circ} 8.243$ [...] também se revela no absurdo cenário que estamos vivendo no Brasil. Tentativas de controlar a mídia através de mecanismos de regulação econômica e de conteúdo, o inchaço da máquina pública (p.ex.40 ministérios!!!), aparelhamento do Estado, através da colocação de quadros políticos em cargos técnicos chave (como se viu nos recentes escândalos da Petrobrás), a tentativa de controle do Poder Legislativo, com a impressionante edição de medidas provisórias e urgências constitucionais etc. (BRASIL, 2014c, p. 13).

O argumento dos deputados Mendonça Filho (DEM) e Ronaldo Caiado (DEM) é sistemático no sentido de fazerem uma leitura conjuntural do quadro político brasileiro. Variados aspectos da PNPS são associados aos implícitos interesses subversivos da Presidente da República. A conceituação de sociedade civil na PNPS/SNPS expressaria, na visão do relator, um interesse de selecionar segmentos específicos da sociedade para apoiar a agenda do governo - relegando cidadãos não organizados à posição secundária (BRASIL, 2014c, p. 12). A expansão do "controle social" gera espanto aos deputados-autores, entendendo-o como uma forma clara e manifesta de ocupar o espaço do Legislativo. Já a associação entre participação e políticas públicas é parte da "aberração" que é a PNPS, com resultados desconhecidos para as políticas (BRASIL, 2014c, p. 12).

A justificativa dada por Caiado e Mendonça Filho é contra a PNPS ou contra qualquer forma de participação externa à representação? $\mathrm{Na}$ justificativa fica claro para os autores que as regulaçóes existentes esgotam o escopo que cabe à participação. E mais, que ela é dada pelo voto: "[o acesso amplo e irrestrito de qualquer cidadão é garantido] dentre outros dispositivos, pelo art. 14 da Carta Magna, que reza: 'A soberania popular será exercida pelo sufrágio universal, e pelo voto direto e secreto" (BRASIL, 2014c, p. 13).

Para os autores, a representação é uma forma que finda a participação. A participação direta e a deliberação seriam externas à constitucionalidade. Nesse sentido, há um radicalismo dos autores - como sinônimo de rechaçar totalmente uma ideia, sem a realização de ressalvas. 
A partir dessa leitura, propóe-se o seguinte pacote interpretativo, que coloca a PNPS como problema a ser resolvido e identifica como os deputados reacionários a ela percebem a situação:

Quadro 3 - PDL n $1.491 / 2014$

\begin{tabular}{|l|l|}
\hline Núcleo da Questáo & A PNPS visa alterar o sistema político. \\
\hline Núcleo da Posiçáo & Sustar por completo o decreto instaurador. \\
\hline $\begin{array}{l}\text { Caracterizaçóes/ } \\
\text { Responsabilizaçáo }\end{array}$ & $\begin{array}{l}\text { A soberania popular é dada por meio do voto/A presidenta Dilma Rousseff } \\
\text { é autoritária subversiva. }\end{array}$ \\
\hline Causas & O problema é a inconstitucionalidade do decreto presidencial. \\
\hline Consequências & A PNPS gera atos discricionários fora da competência do Poder Executivo. \\
\hline Princípios & Manter protegido o sistema democrático representativo. \\
\hline
\end{tabular}

Fonte: Elaboração própria.

Para Santos e Tanscheit (2019), a articulação em torno do impeachment da Presidente Dilma Rousseff já indicava a ascensão de um movimento partidário radicalizado e despreocupado com a democracia. $\mathrm{O}$ conservadorismo em relaçáo à inovação democrática e o caráter exacerbado e acusatório do discurso dos senadores exprimem parte desse novo fenômeno político. Depreende-se desse pacote interpretativo, principalmente, que o aprofundamento democrático deixa de ser uma preocupação comum a atores ideologicamente distantes.

No Senado a proposta foi tocada sob o tom da constitucionalidade ou náo da PNPS. O relator da Comissão de Constituição, Justiça e Cidadania (CCJ), Senador Pedro Taques, se apoia no caráter legiferante ou não da PNPS. Essa posição consiste na inviabilidade institucional de o Executivo produzir, via decreto, leis ou regulaçóes que acabem gerando impactos no conjunto de leis existentes - o que seria atribuição do Legislativo:

Quanto ao mérito do projeto, é importante analisarmos a extensão da competência regulamentar do Poder Executivo, cotejando com as disposiçóes da lei regulamentada, em contraponto ao grau de profundidade do Decreto n. 8.243, de 2014, para se aquilatar se este se limitou a um ambiente próprio ou se atingiu matéria reservada a competência do Poder Legislativo. [...]. Consoante esclarece Celso Antônio Bandeira de Mello, "inovar quer dizer introduzir algo cuja preexistência não se pode conclusivamente deduzir da 'lei regulamentada', 
verificando-se inovação proibida toda vez que não seja possível 'afirmar-se que aquele específico direito, dever, obrigação, limitação ou restrição incidentes sobre alguém não estavam estatuídos e identificados na lei regulamentada" [...] (BRASIL, 2014b, p. 2-3).

No entendimento do relator, o Decreto $\mathrm{n}^{\circ}$ 8.243/2014 atribui condiçôes legiferantes ao Legislativo, sendo o PDL n ${ }^{\circ}$ 147/2014 tido como procedente.

Para além da adequação à constitucionalidade, a relatoria problematiza a capacidade de representação que atores específicos da sociedade civil poderiam portar e menciona a existência de uma crise da representação que náo pode ser resolvida por atores estranhos e sem responderem aos critérios de elegibilidade aplicados aos demais cargos públicos, como, por exemplo, a Lei da Ficha Limpa. Entretanto, o Senador e Relator Pedro Taques (PDT) faz questão de enfatizar que defende a participação institucionalizada e que ela possui espaço no contexto político brasileiro (BRASIL, 2014b).

Do exposto, pode-se sintetizar o seguinte pacote interpretativo da posição do relator em relação à PNPS:

Quadro 4 - Relator Sen. Pedro Taques (PDT)

\begin{tabular}{|l|l|}
\hline Núcleo da Questão & $\begin{array}{l}\text { A PNPS é bem-intencionada, mas inconstitucional e não resolve os } \\
\text { problemas da crise de representação que se propóe a resolver. }\end{array}$ \\
\hline Núcleo da Posiçáo & Apoiar o processo de demoção da PNPS. \\
\hline $\begin{array}{l}\text { Caracterizaçóes/ } \\
\text { Responsabilizaçáo }\end{array}$ & $\begin{array}{l}\text { A participação é possível e deve ser encorajada/Não há responsáveis } \\
\text { específicos. }\end{array}$ \\
\hline Causas & É inconstitucional porque tem caráter legiferante. \\
\hline Consequências & $\begin{array}{l}\text { Concede posiçóes a atores estranhos ao sistema político sem o devido } \\
\text { controle sobre a seleção desses atores. }\end{array}$ \\
\hline Princípios & Expandir a participação sem interferir na ordem constitucional existente. \\
\hline
\end{tabular}

Fonte: Elaboraçáo própria.

Mesmo que surtindo veto sobre a participação, a posição defendida pelo Relator Senador Pedro Taques (PDT) ainda resguarda ideias e valores presentes em outras conjunturas - de expansão da participação -, restando a discordância desse ator em relação à forma como foi dada tal implementação.

A disputa sobre IPs no Congresso Nacional não se findou com os atores e documentos acima. Eles são a expressão de coalizóes mais largas do que congressistas 
específicos. É sintomático, nesse sentido, que a temática das IPs tenha se alastrado largamente naquela instituição e, também, fora dela, na opinião pública.

$\mathrm{Na}$ seara que foi aberta, a PNPS/SNPS foi acusada de ser "bolivariana"; noutras, senadores, como Ana Rita (PT-ES), articularam audiências públicas para defendê-la; outros se esforçaram em dialogar com os congressistas, propondo decretos semelhantes àquele da PNPS para serem debatidos no Senado, como o Projeto de Lei do Senado $\mathrm{n}^{\circ}$ 309, protocolado em novembro de 2014, do Senador Randolfe Rodrigues-PSOL, e o Projeto de Lei ${ }^{\circ}$ 8.048, apresentado em 29 de outubro de 2014 pelo mesmo partido.

\section{Considerações finais}

Este artigo analisou os processos de formulação e implementação de um conselho e de uma política para a participação institucionalizada a partir de pacotes interpretativos. O objetivo foi evidenciar como ideias sobre as IPs são expressas e como circulam no Congresso Nacional, de forma a implementar ou vetar desenhos institucionais, limites para a ação e outros traços básicos das IPs. Cada caso observado serviu como indicação de uma conjuntura e a comparação entre as mesmas permitiu ver mudanças nos pacotes interpretativos. As ideias presentes em cada uma das conjunturas se diversificaram em relação às justificativas para as açóes sobre as IPs, tanto diante da sua aprovaçáo quanto em relação ao seu veto.

$\mathrm{O}$ processo de formulação do CNDI representou uma conjuntura aberta à participação, desdobrada da constitucionalização dos preceitos participativos e da abertura de atores específicos do Congresso à promoção do conselho. Já o caso da PNPS-SNPS evidenciou uma conjuntura na qual o apoio às IPs não é garantido. Pensar a participação como um valor democrático não é mais tão natural quanto no outro período. Muito pelo contrário, essa conjuntura desdobra em medidas não só de veto à PNPS-SNPS, mas também medidas que pretendem a anulação de IPs diversas.

As flutuaçôes ideacionais mostram que a construção e a implementação das instâncias participativas dependem de agentes dispostos a defendê-las constantemente. Essa é uma premissa do institucionalismo histórico quando preocupado não só com forças políticas de formação institucional, mas também de manutenção. É por essa razão, portanto, que se falou tanto da institucionalização dos conselhos: institucionalização foi sinônimo de expansão numérica e qualitativa dos conselhos em uma agenda de pesquisa das IPs, mas também deve ser relacionada à capacidade de resistência mediante conjunturas adversas. Os mecanismos de reprodução de um 
padrão institucional estáo sempre em jogo, fazendo com que a possibilidade de ação das IPs seja variável.

A partir de cada processo, destacou-se que houve conflitos no Congresso Nacional acerca da legalidade, constitucionalidade, mas também sobre a desejabilidade dos conselhos e IPs - aspectos mais politizados. Viu-se que o Congresso Nacional foi um ambiente de disputa política e que a conjuntura que envolveu cada caso apresentou discursos com posiçôes, ideias e animosidades muito diferentes.

No caso da instauraçáa do Conselho do Idoso, pôde-se ver que a ideologizaçáa da disputa foi bastante inferior em comparação com o caso da PNPS/SNPS. A conjuntura da qual essas legislaçóes fazem parte produz argumentos muito diferentes para o seu processo. O pacote interpretativo observado no caso do CNDI sempre incentivou a sua formulação. Ao longo de mais de dez anos de busca pelo conselho, em momento algum houve ator que entendesse como ilegítima a conformação de formas institucionalizadas de participação.

A disputa pela institucionalização da Política Nacional do Idoso foi conflituosa, tendo sua aprovação dada em 1994. A disputa de movimentos sociais por espaço na agenda governamental e a atribuição orçamentária de melhores pensóes e aposentadorias já existia desde os anos de 1970 (PAZ, 2001). Por tangenciar o setor da Previdência em meio a políticas de contençáo fiscal, a disputa em torno da pasta foi acirrada. Frente a isso, a formulaçáo do Conselho Nacional do Idoso se viu constantemente problematizada até 2002. Pode-se pensar que a engenharia institucional da participação, nesse setor de política, não teve disputas da mesma natureza que a Política Nacional do Idoso. A busca pelo conselho foi menos carregada de vieses ideológicos, sendo estes, na verdade, esvaziados em prol de vetos baseados na técnica legislativa - mais uma vez, denotando uma conjuntura na qual a participação, desde que em sintonia com a legalidade, possui valor e espaço - constataçáo que se opóe às ideias apresentadas na conjuntura observada na PNPS-SNPS.

O ambiente político dos anos de 1990 soprava a favor da institucionalizaçáo de demandas sociais, ainda no fôlego da Constituição Federal de 1988, sendo um período de expansão das IPs no nível municipal e estadual. Mesmo os conselhos de outros setores de políticas, que observaram maior grau de conflito na sua formulação, como o da Assistência Social, tiveram sucesso na construção de Conselhos.

No caso do conselho estudado, o veto possui motivação técnica. Os documentos permitem ver a constante ida e vinda de representantes da coalizão da Política Nacional do Idoso e seu conselho em reuniôes com legisladores. Apesar do veto, não há um ambiente hostil à ideia da participação, tanto que, ao fim, em 2002, a 
trajetória do Conselho Nacional dos Direitos do Idoso pôde ser continuada graças às articulaçóes entre atores dali e do Executivo.

As diferenças entre os casos mostram problemas muito relevantes para a implementação ou formulação das IPs. Ambos os casos apresentaram problemas que poderiam gerar vetos: o CNDI esbarrou em uma barreira institucional inicialmente intransponível - a impossibilidade de o Legislativo alterar estruturas do Executivo. Já o caso da PNPS/SNPS se desdobrou de pacotes interpretativos interessados na implementação da participação, mas surpreendeu uma parte dos congressistas por apresentar uma possibilidade de mudança radical no campo da interação entre $o$ sistema representativo, o Executivo e as IPs. Diante das grandes barreiras enfrentadas pelas IPs nos dois casos, o que diferenciou os resultados foi a conjuntura em que se deu o desdobramento do processo político. No caso CNDI, a valorização da participação como parte de um aprofundamento democrático levou os atores à mobilização para a superação da barreira interposta. No caso PNPS/SNPS, imperou um reacionarismo e uma defesa em relação às IPs, o que mobilizou os vetos. Mesmo quando a PNPS/SNPS se tornou projeto de lei, no Congresso, proposta por outros atores, não houve andamento nem diálogos sobre ela. A diferença conjuntural entre os casos afeta diretamente os pacotes interpretativos e os resultados para as IPs.

A comparação do caso do CNDI ao da PNPS evidenciou uma inversão de posições entre o Legislativo e o Executivo. No primeiro caso, não se pôde criar o conselho em funçáo de ser este uma estrutura do Executivo - que deve ser criada pelo Executivo. Nesse ínterim, transcorreu uma década até que esse poder se alinhasse a atores específicos do Legislativo para resultar no Decreto ${ }^{\circ} 4.227 / 2002$. No segundo caso, produziu-se uma inovação legal ao se imprimir relações de representação além do Congresso Nacional - de acordo com os pacotes interpretativos. Ou seja, o Executivo não pôde obter apoio suficiente para evitar o veto de sua política. Desse desencontro quer-se destacar que as instituiçóes tradicionais da democracia importam para a institucionalização das IPs. O timing e a coordenação entre ambos, como evidenciado, foram extremamente condicionantes do veto e da criação dessas IPs.

No caso da PNPS/SNPS, o veto é acompanhado por um discurso inflamado e acusatório. O ambiente político que ronda os anos de 2014 é completamente diferente daquele de 1990. É o período no qual se tenta explicar a ascensão de movimentos antidemocráticos radicalizados (SANTOS e TANSCHEIT, 2019), e isso produziu resultados diferentes sobre essa forma de implementação das instituiçôes participativas. A principal diferença entre as conjunturas foi o abandono da defesa da democracia 
como bem em si mesmo. Essa é uma ideia que orientou muitos atores políticos, inclusive os do "campo democrático popular", mencionado por Pontual e que atuavam nas IPs (GURZA LAVALLE E SZWAKO, 2014, p. 3), à criação de conselhos ao longo dos anos de 1990. E o interesse no aprofundamento da democracia era um componente em comum, mesmo que em formas diferentes, na dicotomia partidária brasileira historicamente constituída desde 1988 (esquerda petista e direita moderada plural).

A movimentação conservadora, então em construção no Congresso Nacional, em 2014, tende a ser associada à ascensão de partidos e atores conservadores até a eleição de Jair Bolsonaro (SANTOS e TANSCHEIT, 2019). Esse movimento pode significar uma ruptura com a valorização da democracia, valor típico da redemocratização. Entretanto, não se pretende construir argumentos a partir de processos históricos muito recentes e ainda em interpretação pela comunidade científica. O que se argumenta é que havia mudanças em curso no Congresso Nacional que afetaram a interpretação dominante nessa instituição acerca da participação institucionalizada. O Congresso Nacional do ano de 2015 se tornou terreno movediço e de disputas políticas sobre o espaço e a função das IPs.

Nesse contexto, é perceptível um gradiente de ideias a respeito da participação institucionalizada. Esse gradiente possui posiçôes enfáticas a seu favor, expressas em Pedro Pontual e outros defensores da PNPS, associados aos partidos à esquerda do espectro político. Posição esta que gera estranhamento e revolta em outros partidos, mais associados ao centro, embora de frágil rigor ideológico, como o DEM de Caiado e Mendonça Filho, que, junto a outros congressistas, travaram uma luta reativa ao PNPS/SNPS. Por outro lado, também foram encontradas posiçóes medianas: a expressão desse caso no Senado focalizou a técnica legislativa para vetar o PNPS/SNPS, embora estimasse abertamente a participação extraparlamentar.

Marcos Luiz Vieira Soares Filho é Doutorando em Ciência Política do Instituto de Estudos Sociais e Políticos da Universidade do Estado do Rio de Janeiro (IESP-UERJ), Bolsista da Fundação Carlos Chagas Filho de Amparo à Pesquisa do Estado do Rio de Janeiro. Email para contato: marcoslvs@yahoo.com.br. 


\section{Referências}

ALMEIDA, Carla; TATAGIBA, Luciana. Os conselhos gestores sob o crivo da política: balanços e perspectivas. Serv. Soc. Soc., v. 109, p. 68-92, 2012.

AVRITZER, Leonardo. A qualidade da democracia e a questão da efetividade da participação: mapeando o debate. In: PIRES, Roberto Rocha Coelho (Org.). Efetividade das instituiçóes participativas no Brasil: estratégias de avaliação. Brasília: IPEA, 2011. p. 13-25.

BRASIL. Câmara dos Deputados. Projeto de Decreto Legislativo $n^{\circ} 1.491$, de 2014. Susta a aplicação do Decreto $n^{\circ}$ 8.243, de 23 de maio de 2014, que institui a Política Nacional de Participação Social PNPS e o Sistema Nacional de Participação Social - SNPS, e dá outras providências. Brasília: Câmara dos Deputados, 2014a.

BRASIL. Senado Federal. Parecer, 2014. Da Comissão de Constituição, Justiça e Cidadania, sobre o Projeto de Decreto Legislativo $n^{\circ} 147$, de 2014, do Dep. Mendonça Filho e outros Deputados, que "susta a aplicação do Decreto $n^{\circ} 8.243$, de 23 de maio de 2014, que institui a Política Nacional de Participação Social - PNPS e o Sistema Nacional de Participação Social - SNPS, e dá outas providências. Brasília: Senado Federal, 2014b. Disponível em: <https://legis.senado.leg.br/sdleggetter/documento?dm=4775006\&ts=1594017756969\&disposition=inline>. Acesso em: $29 \mathrm{mar}$ 2021.

BRASIL. Senado Federal. Projeto de Decreto Legislativo $n^{\circ} 147$, de 2014. Susta a aplicação do Decreto $\mathrm{n}^{\circ}$ 8.243, de 23 de maio de 2014, que institui a Política Nacional de Participação Social - PNPS e o Sistema Nacional de Participação Social - SNPS, e dá outras providências. Brasília: Senado Federal, 2014c. Disponível em: <https://legis.senado.leg.br/sdleggetter/documento? $\mathrm{dm}=4774997 \& \mathrm{ts}=1594017756880 \&$ disposition=inline $>$. Acesso em: $17 \mathrm{dez}$. 2020.

BRASIL. Lei $n^{\circ} 10.741$, de $1^{\circ}$ de outubro de 2003. Dispóe sobre o Estatuto do Idoso e dá outras providências. Brasília, 1 out. 2003. Disponível em: <http://www.planalto.gov.br/ccivil_03/leis/2003/110.741.htm>. Acesso em: 25 mar. 2021.

BRASIL. Senado Federal. Pronunciamento de Leomar Quintanilha em 05/03/2002. Brasília: Senado Federal, 2002a. Disponível em: <https://www25.senado.leg.br/web/atividade/pronunciamentos//p/texto/322689>. Acesso em: $15 \mathrm{dez} .2020$.

BRASIL. Senado Federal. Pronunciamento de Leomar Quintanilha em 21/02/2002. Brasília: Senado Federal, 2002b. Disponível em: <https://www25.senado.leg.br/web/atividade/pronunciamentos//p/texto/322221>. Acesso em: 15 dez. 2020.

BRASIL, Senado Federal. Decreto ${ }^{\circ}$ 4.227, de 13 de maio de 2002. Cria o Conselho Nacional do Idoso - e dá outras providências. Brasília, Senado Federal: 2002c. Disponível em: http://www.planalto.gov.br/ccivil_03/decreto/2002/D4227.htm. Acesso em 29 mar 2021.

BRASIL. Projeto de Lei $n^{\circ} 3.561$, de 1997. Dispóe Sobre o Estatudo do Idoso e dá outras providências. Brasília: Câmara dos Deputados, 1997. Disponível em: <http://www.camara.gov.br/proposicoesWeb/prop_mostrarintegra?codteor=1130962\&filename=Do ssie+-PL+3561/1997>. Acesso em: 08 ago. 2019.

BRASIL. Senado Federal. Mensagem de veto $n^{\circ}$ 3, de janeiro de 1994. Brasília: Senado Federal, 1994. Disponível em: <https://www2.camara.leg.br/legin/fed/lei/1994/lei-8842-4-janeiro-1994-372578veto-23663-pl.html>. Acesso em: 17 fev. 2021. 
BRASIL. Senado Federal. Projeto de Lei $n^{\circ} 112 / 1990$. Fixa diretrizes para a Política Nacional de Assistência ao Idoso, e dá outras providências. Brasília: Senado Federal, 1990. Disponível em: $<$ http://www.camara.gov.br/proposicoesWeb/fichadetramitacao?idProposicao=228634>. Acesso em: 17 fev. 2021.

COLLIER, Ruth Berins; COLLIER, David. Shaping the political arena: critical junctures, the labor movemente, and regime dynamics in Latin America. [S. l.: s. n.], 2002.

FIORETOS, Orfeo; FALLETI, Tulia G.; SHEINGATE, Adam (Orgs.). The Oxford Handbook of Historical Institutionalism. [S.l.]: Oxford University Press, 2016.

FUKS, Mario. Arenas de Ação e Debate Públicos: Conflitos Ambientais e a Emergência do Meio Ambiente enquanto Problema Social no Rio de Janeiro. Dados, v. 41, n. 1, p. 87-113, 1998.

GOHN, Maria da Glória. Conselhos gestores e participação sociopolítica. 4. ed. São Paulo: [s. n.], 2011. GUICHENEY, Hellen. Provisáo municipal de bem-estar social: o papel dos conselhos sobre a gestão, fiscalização e definição de políticas e serviços no plano local. 2019. 235 f. Tese (Doutorado em Ciência Política) - Programa de Pós-Graduação em Ciência Política, Universidade de São Paulo (USP), São Paulo, 2019.

GURZA LAVALLE, Adrián Gurza; SZWAKO, José. Origens da Política Nacional de Participação Social: Entrevista com Pedro Pontual. Novos Estudos - CEBRAP, n. 99, p. 91-104, 2014.

HADDAD, Eneida G. de Macedo. $O$ direito à velhice: os aposentados e a previdência social. 2. ed. Sáo Paulo: Cortez, 2001.

HALL, Peter A. Politics as a Process Structured in Space and Time. [S.l.]: Oxford University Press, 2016. v. 1.

LACERDA, Marina Basso. Neoconservadorismo: punitivismo, familismo e neoliberalismo na Câmara dos Deputados. 2018. 207 f. Tese (Doutorado em Ciência Política) - Programa de Pós-Graduação em Ciência Política, Universidade do Estado do Rio de Janeiro (UERJ), Rio de Janeiro, 2018.

LÜCHMANN, Lígia Helena Hahn. Associações, participação e representação: combinaçóes e tensôes. Lua Nova: Revista de Cultura e Política, n. 84, p. 353-364, 2011.

LÜCHMANN, Lígia Helena Hahn. A representação no interior das experiências de participação. Lua Nova: Revista de Cultura e Política, n. 70, p. 139-170, 2007.

PAZ, Serafim Fortes. Dramas, cenas e tramas: a situação de foruns e conselhos do idoso no Rio de Janeiro. 2001. 762 f. Tese (Doutorado em Políticas Públicas) - Faculdade de Educação, Universidade Estadual de Campinas (UNICAMP), Campinas, 2001.

POGREBINSCHI, Thamy; SANTOS, Fabiano. Participação como representação: o impacto das conferências nacionais de políticas públicas no Congresso Nacional. Dados, v. 54, p. 259-305, 2011.

ROMÃO, Wagner De Melo. Reflexôes sobre as dificuldades da Implementação da participação Institucional no brasil. Idéias, v. 6, p. 35-58, 2015.

SANTOS, Fabiano; TANSCHEIT, Talita. Quando velhos atores saem de cena: a ascensão da nova direita política no Brasil. Colombia Internacional, n. 99, p. 151-186, 2019.

SIMIS, Anita. Conselho de comunicação social: uma válvula para o diálogo ou para o silêncio? Rev. bras. Ci. Soc., v. 25, n. 72, p. 59-174, 2010.

SOARES FILHO, Marcos Luiz Vieira. Tensôes e incentivos do Legislativo nacional à formulação e implementação das instituições de participação: o caso do Conselho Nacional dos Direitos do Idoso e da Política e Sistema Nacional de Participação Social. In: ENCONTRO INTERNACIONAL PARTICIPAÇÃO, DEMOCRACIA E POLÍTICAS PÚBLICAS, 4., 2019, Porto Alegre. Anais do 
IV Encontro Internacional Participação, Democracia e Políticas Públicas. Porto Alegre, 2019. p. 123.

SOARES FILHO, Marcos Luiz Vieira. Entre o ideal e os resultados da trajetória histórica dos conselhos públicos: a interação Estado-sociedade no caso do Conselho Estadual de Defesa dos Direitos da Pessoa Idosa entre 2009-2017. 2018. 158 f. Tese (Doutorado em Ciência Política) -Programa de PósGraduação em Ciência Política da Universidade Federal Fluminense, Niterói, 2018.

SOIFER, Hillel David. The Causal Logic of Critical Junctures. Comparative Political Studies, v. 45, n. 12, p. 1572-1597, 2012.

SOUZA, Luciana. Do local para o nacional: o orçamento participativo e as novas práticas políticas petistas. 2011. 197 f. Tese (Doutorado em Ciência Política) - Programa de Pós-Graduação em Ciência Política, Universidade Federal de São Carlos (UFSCar), São Carlos, 2011.

Texto recebido em 21 de dezembro de 2020. Aprovado em 11 de fevereiro de 2021. 